\title{
Experimental evaluation of chemical resistance of steatite products towards aluminum-based melts
}

\author{
N. K. Orlov ${ }^{1}$, D. A. Kozlov ${ }^{1}$, S. A. Tikhonova ${ }^{1}$, A. A. Tikhonov ${ }^{1}$, A. V. Garshev ${ }^{1,2, *}$, P. V. Evdokimov ${ }^{1,2}$, \\ V. I. Putlayev ${ }^{1,2}$, A. A. Vasyakov ${ }^{3}$, A. V. Chetvertukhin ${ }^{3}$, A. K. Petrov ${ }^{3}$, I. Yu. Mikhailov ${ }^{4}$, \\ S. V. Polyakov ${ }^{5}$, A. A. Fedyanin ${ }^{3}$ \\ ${ }^{1}$ Faculty of materials science, Lomonosov Moscow State University, Moscow, Russia \\ ${ }^{2}$ Faculty of Chemistry, Lomonosov Moscow State University, Moscow, Russia \\ ${ }^{3}$ Faculty of Physics, Lomonosov Moscow State University, Moscow, Russia \\ ${ }^{4}$ LLC Light Materials and Technologies Institute, Moscow, Russia \\ ${ }^{5}$ JSC Russian Aluminium Management, Moscow, Russia \\ nicolasorlov174@gmail.com, kozlov@inorg.chem.msu.ru, *garshev@inorg.chem.msu.ru, \\ vasyakov@nanolab.phys.msu.ru, chetvertukhin@nanolab.phys.msu.ru, Ivan.Mikhaylov@rusal.com, \\ fedyanin@nanolab.phys.msu.ru
}

\begin{abstract}
The processes taking place with a spray unit during aluminum dispersion have been analyzed. It has been shown that the major process which occurs in a nipple during aluminum flowing is the reduction of silicon with aluminum and, also, with magnesium from the melt (in case when aluminum-magnesium or magnesium-containing alloys are used). The reduction of silicon results in the formation of nanoscale particles with crystalline size $20-50 \mathrm{~nm}$ and leads to the degradation of the nipple material, which is accompanied by its cracking and the formation of nanoscale channels and the flow of melt into the material through these channels. This phenomenon leads to the rupture and/or blockage of the nipple.
\end{abstract}

Keywords: aluminum alloys, steatite, steatite nipple, AK7 alloy.

Received: 14 August 2019

Revised: 30 November 2019

\section{Introduction}

Primary aluminum production is one of the most labor- and energy-intensive processes. Nevertheless, these expenses are compensated by the high demand for the resulting metal, which is ensured by the convenience of using aluminum and its alloys in aircraft and rocketry, in the production of gas blowing agents and pigments [1]. Moreover, powders based on aluminum and its alloys obtained from primary aluminum and the relevant ligatures are widely used in the manufacture of metallic parts by selective laser fusion [2], and the mechanical characteristics of the resulting products are as good as of the cast parts [3]. In many cases, an intermediate technological product is the powder consisting of particles no larger than 100 microns in size, which is produced by the dispersion of molten aluminum and aluminum-based alloys under high pressure by a small diameter nozzle [1]. This method is notable for its simplicity and effectiveness. However, the nozzle material (for example, ceramics based on steatite — a natural mineral based on talc, magnesite, and chlorite [4]) is prone to a gradual loss of its initial properties due to the reaction with the flowing melt.

\section{Materials and methods}

Steatite nipples were made by molding a mixture of pre-ground steatite and liquid glass. After molding, the nipples were dried in a muffle furnace at a temperature of $270^{\circ} \mathrm{C}$, and then they were again immersed into liquid glass and kept at the same temperature. Then the nipples were held at a temperature of $600{ }^{\circ} \mathrm{C}$.

To study the interaction of steatite nipples with aluminum melt, the small nipple samples in an AK7ch alloy melt were isothermally treated for $6,12,24$, and 48 hours at temperatures of $700{ }^{\circ} \mathrm{C}$ and $850{ }^{\circ} \mathrm{C}$. The experiments were carried out in a Nabertherm $\mathrm{N} 7 / \mathrm{H}$ resistance muffle furnace under air atmosphere. Then the nipple samples were taken out of the furnace and cooled to a room temperature in the air.

In addition, to verify the possibility of interaction of the aluminum melt with the nipple material, the annealing of the nipple material crushed in the mortar with AK7ch alloy powder was performed. The experiment was carried out in an STA 409 PC Luxx thermal analyzer (Netzsch, Germany) under an argon flow (150 ml/min) with preliminary air evacuation. 
The studying of the nipple after aluminum dispersion was carried out using a sample obtained from the factory of aluminum powder production. To determine the composition of the reaction layer, the samples were poured into Struers SpeciFix-20 epoxy resin and ground using a Struers DAP-V grinding-polishing machine (Struers, Germany) in accordance with the guidelines [8].

X-ray phase analysis was carried out on a Rigaku D/Max-2500 instrument (Rigaku, Japan) with a mounted rotating anode. In the course of the experiment, $\mathrm{CuK} \alpha_{1,2}$ radiation was used; the experiment was conducted in a reflection mode. The samples were applied onto zero-background silicon cuvettes; the data was collected in the range of angles of $5-90^{\circ} 2 \theta$ with an increment of $0.02^{\circ} 2 \theta$ and the signal accumulation time of $0.5 \mathrm{~s}$. The obtained X-ray patterns were analyzed using WinXPOW software with the ICDD PDF-2 database.

Thermal analysis combined with the evolved gas mass spectrometry, was conducted using STA 409 PC Luxx thermal analyzer (Netzsch, Germany) with vertical loading of samples and an Aëolos QMS 403 C quadrupole mass spectrometer (Netzsch, Germany) with heating of the inlet capillary system. The experiments were carried out in alundum crucibles in the temperature range from $40{ }^{\circ} \mathrm{C}$ to $1200{ }^{\circ} \mathrm{C}$ with the heating rate of $10{ }^{\circ} \mathrm{C} / \mathrm{min}$ under an air atmosphere. The weight of the samples did not exceed $100 \mathrm{mg}$.

To obtain microscopic images, the pre-polished samples were examined using a LEO SUPRA 50 VP scanning electron microscope (Zeiss, Germany) using an X-MAX 80 energy dispersive detector (OxfordInst., United Kingdom). The accelerating voltage was set as $20 \mathrm{keV}$, the data was collected in the mapping mode with a signal accumulation time of 30 minutes. To calculate the elemental composition, the INCA Oxford software package was used in semiautomatic mode. Optical images of the specimens were obtained using an Olympus BX41 optical microscope.

\section{Results and discussion}

To study the change in the elemental composition during the interaction of the nipple material with the aluminum melt, the samples obtained during isothermal treatment in the furnace were studied by EDX microanalysis. According to the obtained data, the initial nipple contained about $3 \% \mathrm{Na}, 0.6 \% \mathrm{~K}, 7 \% \mathrm{Al}, 14 \% \mathrm{Si}, 8 \% \mathrm{Mg}, 0.06 \% \mathrm{Ti}$, and $5 \%$ $\mathrm{Fe}$ (atomic \%). It should be noted that the nipple is made from the natural mineral steatite with the addition of liquid glass, and therefore its composition is significantly different from the point of the analysis.

Thermal analysis (Fig. 1) of the nipple material showed a mass loss of $11 \%$ with the release of $\mathrm{CO}_{2}$ and $\mathrm{H}_{2} \mathrm{O}$ continuing up to $930{ }^{\circ} \mathrm{C}$. The loss of water up to $200{ }^{\circ} \mathrm{C}$ corresponds to the removal of adsorbed water, whereas the loss of water in the range from 400 to $930^{\circ} \mathrm{C}$ corresponds to the decomposition of clinochlore and muscovite. The release of $\mathrm{CO}_{2}$ may correspond to the decomposition of the same clinochlor and muscovite with substituted hydroxy groups into carbonate ones. This substitution does not cause the change in the phase composition due to the structural features of aluminosilicates and this is the reason why the X-ray phase analysis results show the presence of hydroxide forms.

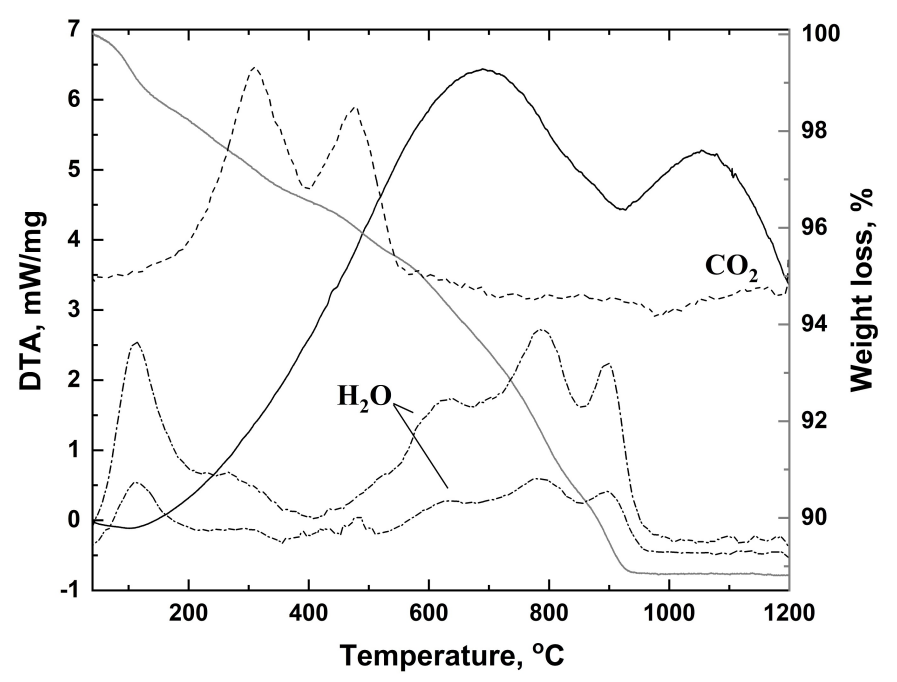

FIG. 1. Thermal analysis of the steatite nipple $(1-$ differential thermal analysis, $2-$ the sample mass loss curve, 3 - the mass spectrum of $\mathrm{H}_{2} \mathrm{O}^{+}$and $\mathrm{OH}^{+}$ions, 4 - the mass spectrum of $\mathrm{CO}_{2}^{+}$ions)

According to the X-ray diffraction patterns obtained from the powders of the initial nipple and the nipple annealed in the presence of aluminum (Fig. 2), the steatite nipple consists of crystalline aluminosilicates: muscovite 
and clinochlore (according to the database of crystal structures, ICDD cards 7-42 and 12-242, respectively). X-ray phase analysis of the samples after annealing at $700{ }^{\circ} \mathrm{C}$ for 48 hours showed that muscovite remains as the predominant phase, whereas clinochlore decomposes (the intensity of its main reflections decreases markedly at 12.5 and $25.1^{\circ} 2 \theta$ ) without the formation of new crystalline phases. After the annealing at $850{ }^{\circ} \mathrm{C}$ for 48 hours, muscovite is also present in the sample, but new phases also appear: forsterite $\left(\mathrm{Mg}_{2} \mathrm{SiO}_{4}\right)$, nepheline $\left(\mathrm{NaAlSiO}_{4}\right)$ and cristobalite $\left(\mathrm{SiO}_{2}\right)$ (according to the database of crystal structures, ICDD, cards 34-189 and 35424 and 76-941, respectively).

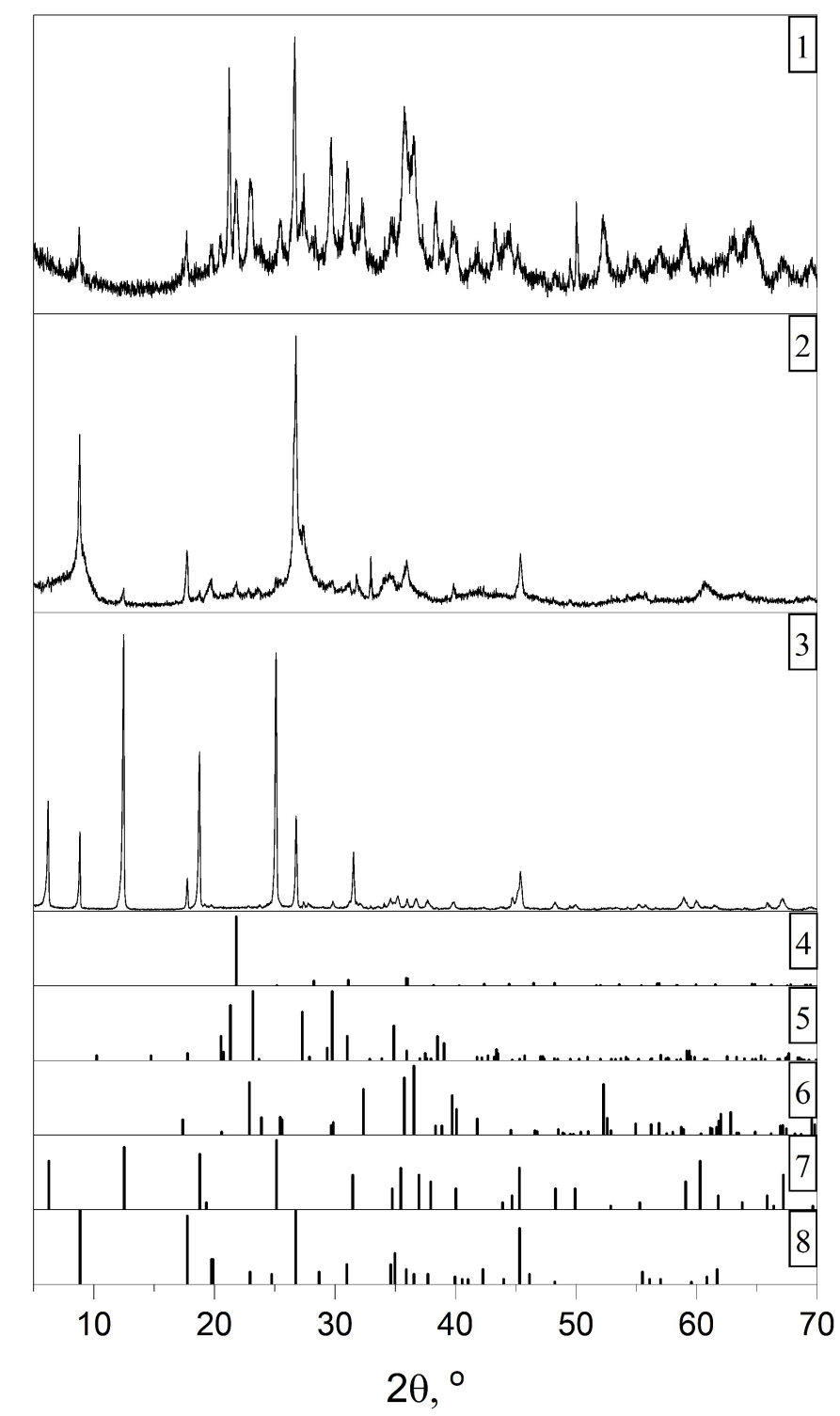

FIG. 2. X-ray phase analysis of the nipple material ( 1 - X-ray diffraction pattern of the nipple after isothermal treatment at $850^{\circ} \mathrm{C}$ during 48 hours; 2 - X-ray diffraction pattern of the nipple after isothermal treatment at $700^{\circ} \mathrm{C}$ during 48 hours, $3-\mathrm{X}$-ray diffraction pattern of the initial nipple; 4 - the positions of cristobalite reflections, $\mathrm{SiO}_{2}$ ICDD [76-941], 5 - the positions of nepheline reflections $\mathrm{NaAlSiO}_{4}$ ICDD [35-424], 6 - the positions of forsterite reflections $\mathrm{Mg}_{2} \mathrm{SiO}_{4}$ ICDD [34-189], 7 - the positions of clinochlore reflections $(\mathrm{Mg}, \mathrm{Al})_{6}(\mathrm{Si}, \mathrm{Al})_{4} \mathrm{O}_{10}(\mathrm{OH})_{8} \mathrm{ICDD}$ [12-242], 8 - the positions of muscovite reflections, $\left.(\mathrm{K}, \mathrm{Na})(\mathrm{Al}, \mathrm{Mg}, \mathrm{Fe})_{2}(\mathrm{Si}, \mathrm{Al})_{4} \mathrm{O}_{10}(\mathrm{OH})_{2} \mathrm{ICDD}[7-42]\right)$

Thus, according to the data of thermal and X-ray phase analysis, we can conclude that during the exploitation of steatite nipples at the melting temperatures of aluminum and its alloys $\left(650{ }^{\circ} \mathrm{C}-900{ }^{\circ} \mathrm{C}\right)$, a noticeable degradation of the material occurs with a change in the phase composition of the nipple. 
Fig. 3 shows the SEM image and the elements distribution maps of $\mathrm{Al}, \mathrm{Mg}$, and $\mathrm{Si}$ at the boundary of the nipple sample with the melt after holding at $700{ }^{\circ} \mathrm{C}$ for 6 hours. Besides the region of aluminum metal (Al map) and the nipple region ( $\mathrm{Mg}$ and $\mathrm{O}$ maps), a region containing elevated concentrations of magnesium, aluminum, and oxygen was also found at the melt boundary. Probably, this accumulation of magnesium at the melt boundary is caused by the oxidation-reduction (redox) reactions on the surface of the nipple, which is presumably accompanied by the oxidation of magnesium metal from the melt and the reduction of iron and silicate ions to nanosized Fe or Si impurities: 4Almelt $+3 \mathrm{SiO} 2=2 \mathrm{Al} 2 \mathrm{O} 3+3 \mathrm{Simelt}$

$$
\begin{gathered}
4 \mathrm{Al}_{\text {melt }}+3 \mathrm{SiO}_{2}=2 \mathrm{Al}_{2} \mathrm{O}_{3}+3 \mathrm{Si}_{\text {melt }}, \\
2 \mathrm{Mg}_{\text {melt }}+\mathrm{SiO}_{2} \rightarrow 2 \mathrm{MgO}+\mathrm{Si}_{\text {melt }}, \\
2 \mathrm{Fe}^{3+}+3 \mathrm{Mg}_{\text {melt }} \rightarrow 3 \mathrm{Mg}^{2+}+2 \mathrm{Fe}_{\text {melt }} .
\end{gathered}
$$

It should be noted, that these areas contain no other elements presented in the original nipple. Therefore, the probable reaction product may be either $\mathrm{MgO}$, magnesium silicate or magnesium aluminate.

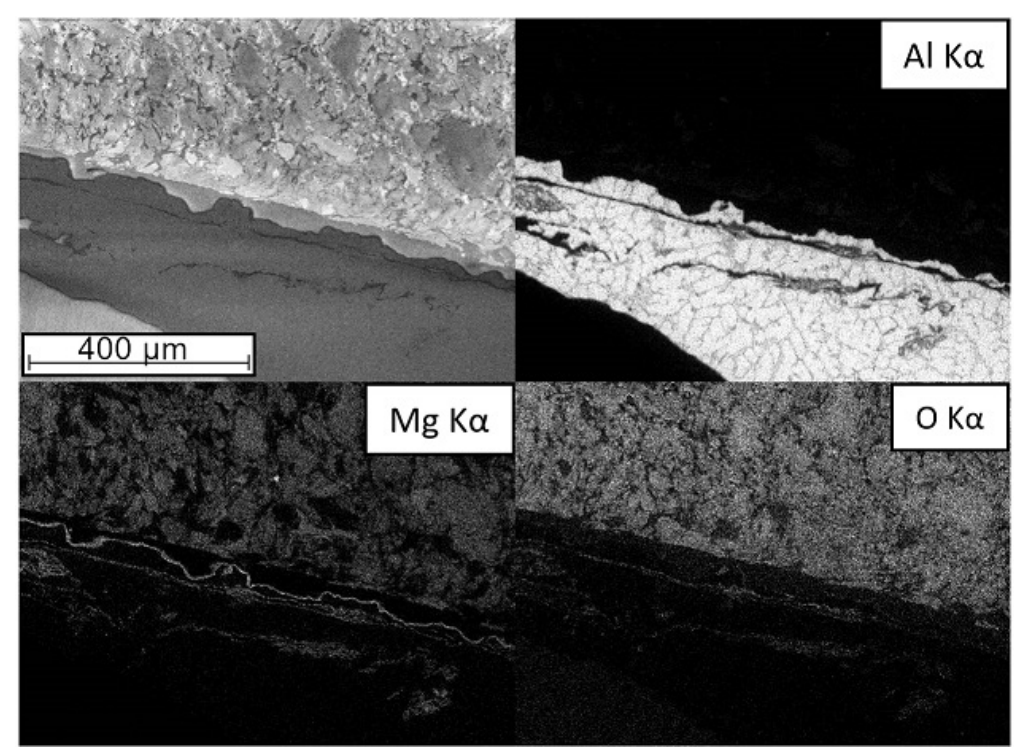

FIG. 3. SEM image in backscattered electrons and the elemental distribution map in the sample obtained during isothermal treatment of steatite in the melt at $700^{\circ} \mathrm{C}$ over 6 hours

The emergence of a magnesium-containing layer is observed on all samples obtained as a result of the interaction of the nipple with aluminum melt. According to the EDX results, the areas of aluminum penetration into the body of the nipple appear with an increase in the isothermal treatment time to 24 hours. The sizes of these areas increase with increasing isothermal treatment time up to 48 hours. Thus, Fig. 4 shows the SEM image of a sample obtained as a result of the interaction of the nipple with the melt at $700{ }^{\circ} \mathrm{C}$ for 48 hours.

According to EDX data, aluminum presents not only in the metal layer near the boundary, but also penetrates into the body of the nipple (the dark region in the SEM image in Fig. 4). In addition, at the boundary of the region of aluminum penetration into the nipple body, a pronounced concentration of sodium is observed, which is caused by the diffusion of sodium ions from the boundary with the melt. This diffusion is probably due to the negative gradient of the chemical potential caused by the redox reactions. It is likely that the interaction of the aluminum melt with the nipple material leads to the reduction of silicates to silicon accompanied by the oxidation of aluminum:

$$
\begin{aligned}
6 \mathrm{Al}_{l i q}+4 \mathrm{SiO}_{3}^{2-} & \rightarrow 3 \mathrm{Al}_{2} \mathrm{O}_{4}^{2-}+4 \mathrm{Si}_{l i q}, \\
4 \mathrm{Al}_{l i q}+3 \mathrm{SiO}_{2} & \rightarrow 2 \mathrm{Al}_{2} \mathrm{O}_{3}+3 \mathrm{Si}_{l i q} .
\end{aligned}
$$

It is worth noting that an increase in the temperature and the treatment time of the nipple in the metal melt leads to an increase in the area of aluminum penetration. This is probably caused by the lowering of the melt viscosity with temperature increase, which results in the penetration of the melt into smaller channels, up to nanoscale ones. On the other hand, the reduction of nanosized silicon leads to the cracking of the ceramic material causing its degradation and an increase in the porosity of the channels. 


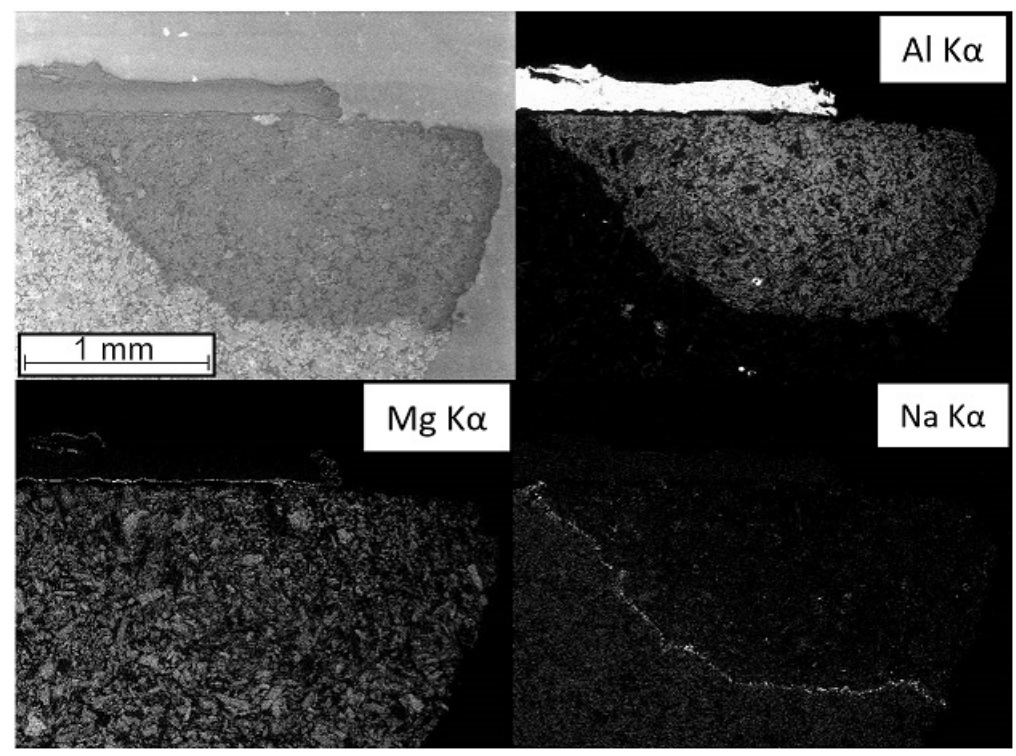

FIG. 4. SEM image in backscattered electrons and the elemental distribution map in the sample obtained during isothermal treatment of steatite in the melt at $700^{\circ} \mathrm{C}$ during 48 hours

In the samples obtained under isothermal treatment at $850^{\circ} \mathrm{C}$, the magnesium-containing layer does not form, apparently, due to the instability of the products of the magnesium layer at the given temperature. In this case, aluminum penetrates into the nipple to a much greater depth, which is related to an increase in the yield strength of the AK7ch alloy.

Figure 5 shows the SEM and element distribution maps of $\mathrm{Al}, \mathrm{Mg}$, and $\mathrm{Si}$ at the boundary between the nipple sample and the melt after exposure at $850{ }^{\circ} \mathrm{C}$ for 24 hours. The greater penetration of aluminum into the body of the nipple is confirmed by the intense $\mathrm{Al}$ signal (Al map) from the entire nipple region ( $\mathrm{Mg}$ map). It is also worth noting that at a given time of isothermal treatment an oxygen signal is present from the entire aluminum region indicating the complete oxidation of aluminum under these conditions.

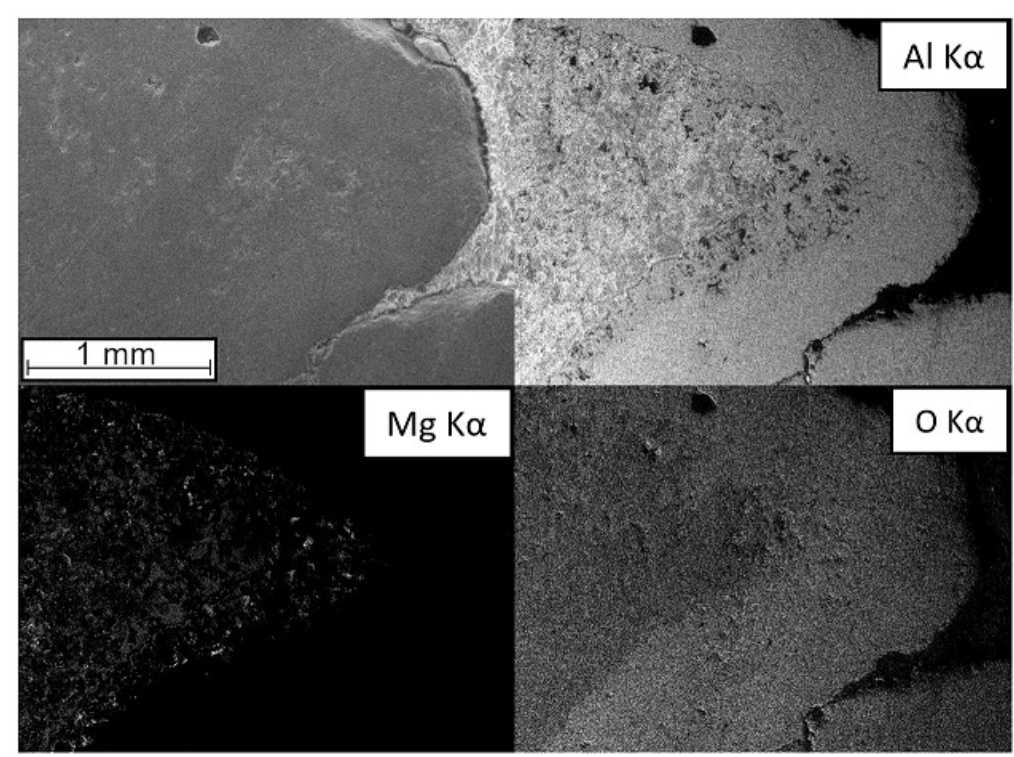

FIG. 5. SEM image in backscattered electrons and the elemental distribution map in the sample obtained during isothermal treatment of steatite in the melt at $850^{\circ} \mathrm{C}$ for 24 hours

According to the EDX data, the accumulation of individual elements $(\mathrm{Na}$ and $\mathrm{Mg}$ ) and the penetration of aluminum into the body of the nipple can be explained by the occurrence of the redox reactions at the boundary of the nipple with the melt: the oxidation of metallic magnesium and aluminum from the melt and the reduction of iron and 


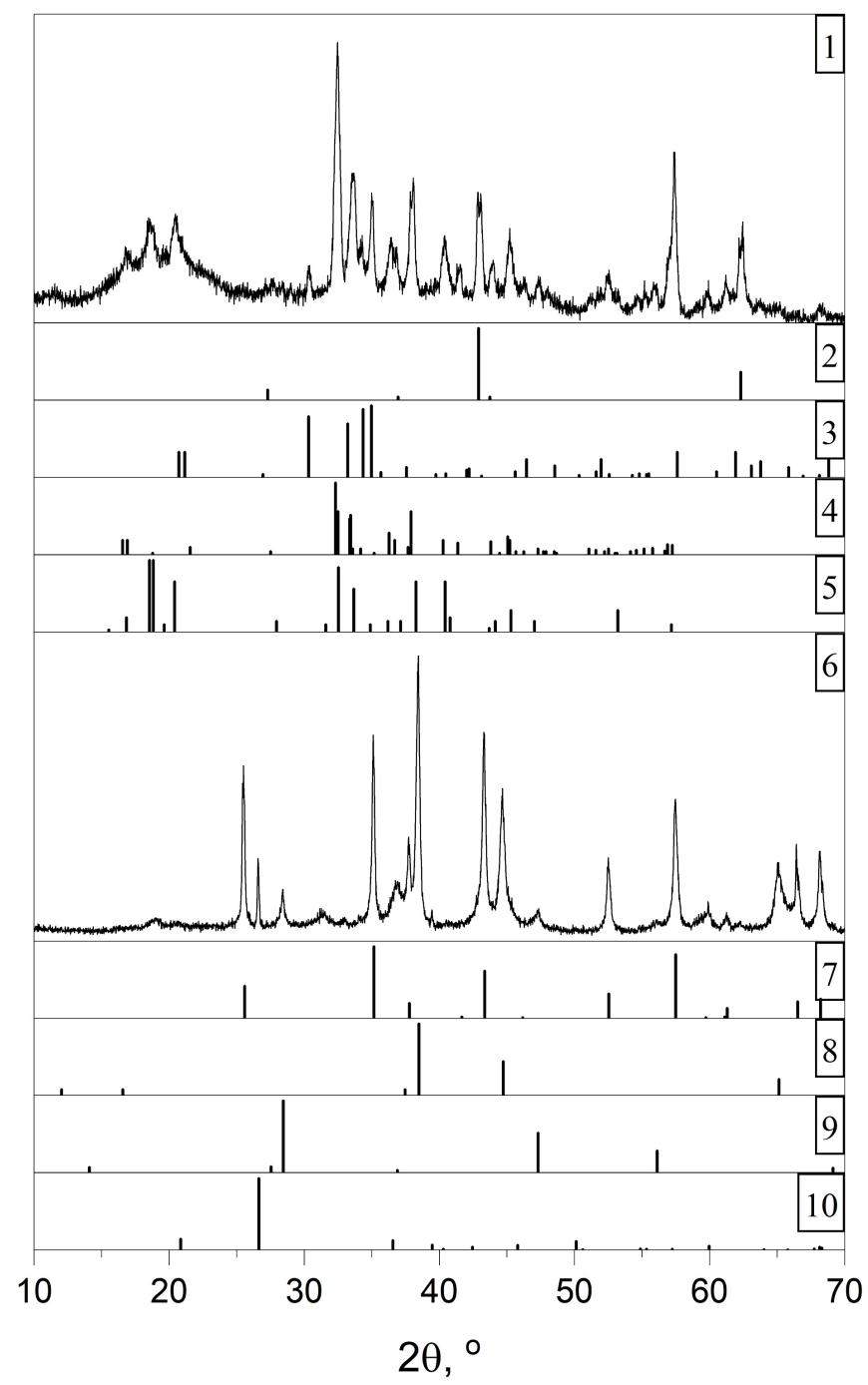

FIG. 6. X-ray phase analysis of the nipple after interaction with the aluminum melt at $850{ }^{\circ} \mathrm{C}$ during 12 hours ( 1 - X-ray diffraction pattern of the region of $\mathrm{Na}$ accumulation; 2 - the positions of $\mathrm{MgO}$ reflections, ICDD [45-946]; 3 - the positions of $\mathrm{NaAlO}_{2}$ reflections, ICDD [331200]; 4 - the positions of thermonatrite $\mathrm{Na}_{2} \mathrm{CO}_{3} \cdot \mathrm{H}_{2} \mathrm{O}$ reflections, ICDD [8-448], 5 - the positions of $\mathrm{Na}_{2} \mathrm{Al}_{2} \mathrm{O}_{4} \cdot 6 \mathrm{H}_{2} \mathrm{O}$ reflections, ICDD [29-1165], 6 - X-ray diffraction pattern of the nipple; 7 - the positions of corundum $\mathrm{Al}_{2} \mathrm{O}_{3}$ reflections, ICDD [46-1212]; 8 - the positions of $\mathrm{Al}$ reflections, ICDD [4787], 9 - the positions of silicon reflections $\mathrm{Si}$, ICDD [27-1402], 10 - the positions of $\mathrm{SiO}_{2}$ reflections, ICDD [791906])

silicates. Thus, we can assume the following mechanism of slag formation: aluminum melt, when flowing through a steatite nipple, partially reduces silicates, transforming into aluminum oxide and aluminates and settles on the walls of the nipple. In turn, at low temperatures, in addition to aluminum oxidation, the reduction of silicates and iron ions by magnesium occurs, leading to the formation of a magnesium-containing layer on the surface of the nipple.

Figure 6 shows the results of XRD analysis of nipple samples after interaction with aluminum melt. The following aluminum-containing phases can be distinguished in the diffraction pattern obtained from the contact area of metallic aluminum with a nipple: metallic aluminum and corundum, and silicon-containing phases - quartz and silicon. The presence of these phases confirms the previously proposed slag formation mechanism (4), according to which, aluminum is oxidized near the surface of the nipple due to the reduction of silicates. The upper X-ray pattern (Fig. 6) corresponds to the boundary of aluminum penetration into the nipple material. According to the results of X-ray phase analysis, after cooling in the air, $\mathrm{Na}_{2} \mathrm{Al}_{2} \mathrm{O}_{4} \cdot 6 \mathrm{H}_{2} \mathrm{O}, \mathrm{Na}_{2} \mathrm{CO}_{3} \cdot \mathrm{H}_{2} \mathrm{O}$ and $\mathrm{NaAlO}_{2}$ phases with a high sodium content are present in this region of the sample confirming the enrichment of this region with sodium which was proved by EDX 


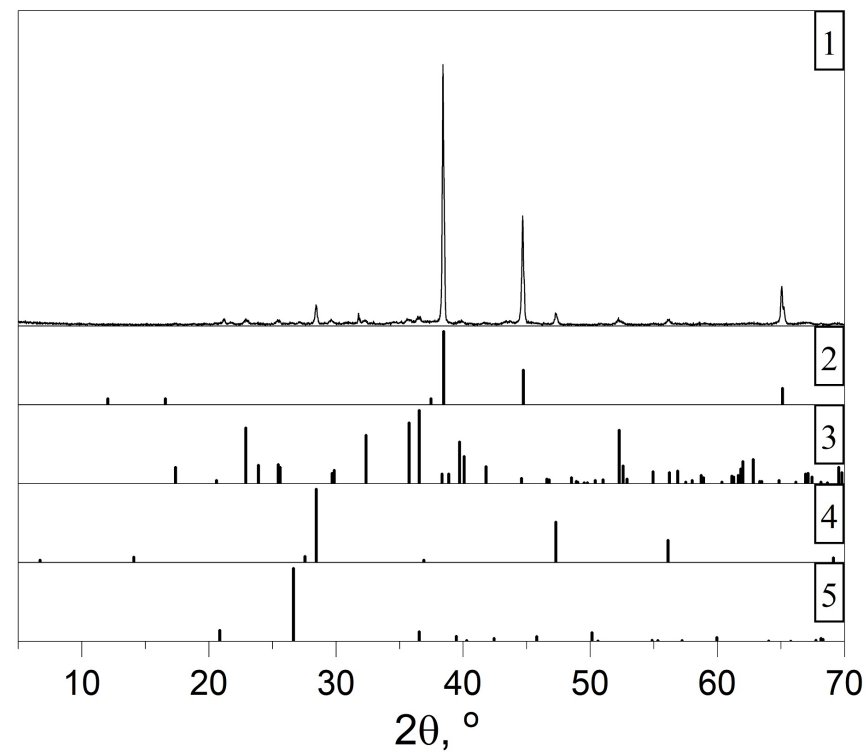

FIG. 7. X-ray phase analysis of the nipple material after grinding with aluminum powder and annealing at $1200{ }^{\circ} \mathrm{C}(1-\mathrm{X}$-ray pattern of the obtained powder; 2 - the positions of $\mathrm{Al}$ reflections, ICDD [4787]; 3 - the positions of forsterite, $\mathrm{Mg}_{2} \mathrm{SiO}_{4}$, reflections, ICDD [34-189]; 4 - the positions of Si reflections [27-1402], 5 - the positions of quartz, $\mathrm{SiO}_{2}$, reflections, ICDD [79-1906])

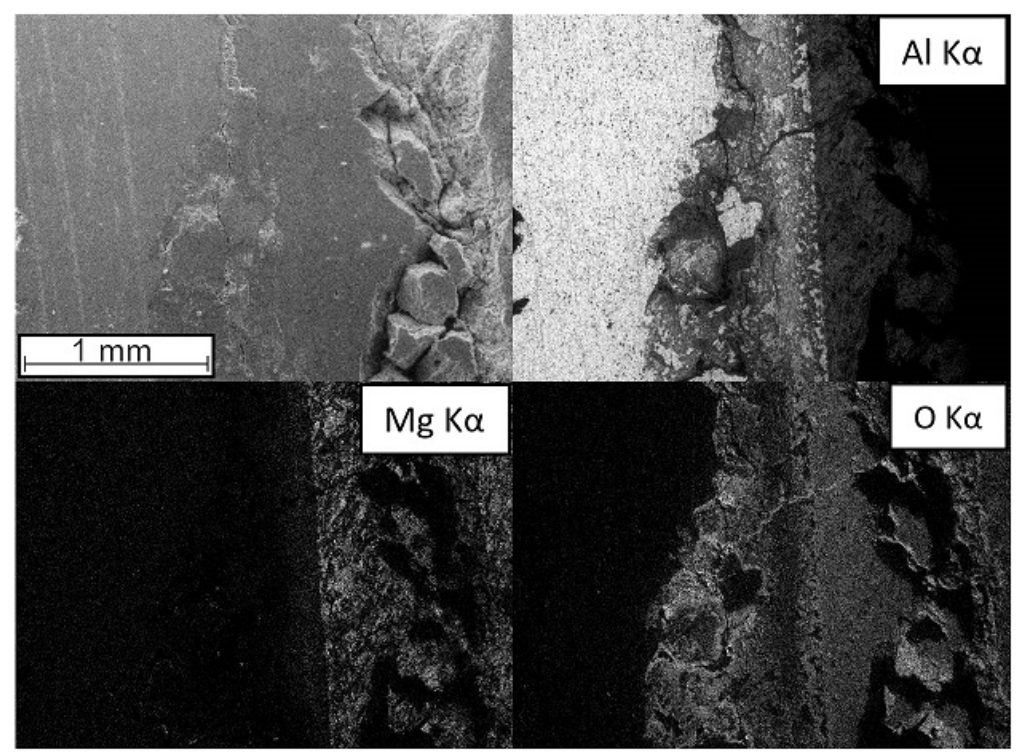

FIG. 8. SEM image in backscattered electrons and elemental distribution maps in the nipple sample obtained from the manufacturer

microanalysis. According to X-ray diffraction data (Fig. 6), the crystallite size of formed silicon crystallites calculated by the Scherrer formula is $21 \pm 3 \mathrm{~nm}$, whereas main aluminum-containing phase corundum has characteristic sizes of crystallites of about $44 \pm 3 \mathrm{~nm}$.

XRD analysis of the sample of aluminum and steatite after annealing in argon confirmed the assumption that silicon is reduced by magnesium and aluminum. The X-ray diffraction pattern shows peaks of pure silicon with crystallites sizes about $100 \mathrm{~nm}$, which were absent in the initial steatite (Fig. 7).

The results of EDX analysis of the nipples after experiments on the aluminum dispersion show a similar picture (Fig. 8).

The sample contains 4 regions that differ in composition. The first region corresponds to the metallic aluminum located near the boundary of the nipple and the melt. Aluminum and oxygen are present in the second region indicating 
that the formation of slag occurs due to the oxidation of aluminum metal on the surface of the nipple. In the third region, $\mathrm{Al}, \mathrm{Si}$, and $\mathrm{O}$ are detected corresponding to the penetration of aluminum into the body of the nipple. It is between the second and third regions where the initial boundary between the nipple and the melt passes, which is confirmed by the even shape of the boundary and the absence of magnesium in the second region. The fourth region corresponds to the nipple material which did not interact with aluminum. Thus, the distribution of elements in the nipple sample confirms the previously proposed mechanism of slag formation on the surface of the nipple as a result of its interaction with the aluminum melt.

\section{Conclusions}

In summary, it was shown that the most probable reason for slag formation on the surface of steatite nipples caused by the interaction with the aluminum melt is the aluminum oxidation accompanied by the aluminum penetration into the body of the nipple. During the reduction of silicon in the steatite by aluminum melt, the nanoscale particles with crystalline size of $20-50 \mathrm{~nm}$ are formed rather than the monolithic layer of the reduction products. Thus reduction process leads to degradation of the nipple material, which is accompanied by its cracking. In this case, the nipple failure can be caused not only by a decrease in the effective diameter of the nipple as a result of the aluminum oxide growth on the inner surface of the nipple, but also by the mechanical instability of the nipple caused both by the removal of gaseous water and carbon dioxide during the nipple heating to the operating temperature and by the degradation of the material during its chemical reduction with molten aluminum.

\section{Acknowledgment}

The work was carried out in the organization of the Lead Executor of R\&D (Lomonosov Moscow State University) under the Agreement No. PSh-218-2017/ 01 dated 02.09.2017 with financial support from the Ministry of Education and Science of the Russian Federation under Agreement No. 075-11-2018-196 dated 04.28.2017 (internal contract number 03.G25.31.0248).

\section{References}

[1] Gopienko V.G., Osipov B.R., Nazarov B.P., Ryumin V.M., Volkov I.V., Yasakov N.I. Production and application of aluminum powders and fine powders. Moscow, 1980, $67 \mathrm{p}$.

[2] Garshev A.V., Kozlov D.A., Evdokimov P. V., Filippov Y.Y., Orlov N.K., Putlyaev V.I., Chetvertukhin A.V., Petrov A.K. Analysis of Aluminum Alloy Powders for Additive Manufacturing Fabricated by Atomization. Inorg. Mater. Appl. Res., 2019, 10, P. 901-905.

[3] Kempen L., Thijs L., Van Humbeeck J., Kruth J.-P. Mechanical properties of AlSi 10 Mg produced by Selective Laser Melting. Phys. Procedia, 2012, 39, P. 439-446.

[4] Bhavan I., Lines C. Indian Minerals Yearbook 2015 Vol. III- Mineral Reviews, Indian Bureau of Mines, Nagpur, 2015,50 p.

[5] Kuksa A.V., Molkov A.V., Gubanov A.V., Linkov S.V. Melt metals spraying jet, RU2321475, 2007.

[6] Arkhipov V.A., Evsevleev M.J., Zhukov A.S., Zmanovskij S.V., Konovalenko A.I., Litvinov A.V. Nozzle for melted metals spraying, RU2554257, 2014.

[7] Kabatsov M.V., Lagutkin S.V. Device for producing metal distribution by melt melt, RU133032, 2013.

[8] Bjerregaard L., Geels K., Ottesen B., Rueckert M. Metalog Guide, Richard Larsen A/S, Rodovre, 1992,115 p. 